$\begin{gathered}\text { Revista do Departamento de Geografia } \\ \text { Universidade de São Paulo } \\ \text { www.revistas.usp.br/rdg }\end{gathered}$
V.32 (2016)

\title{
Uso do Solo e Vulnerabilidade Socioambiental na Sub-Bacia do Alto Rio das Pedras (Rio de Janeiro/RJ): Subsídios para Regeneração de Rios Neotropicais
}

\section{Land Use and Environmental Vulnerability in the Sub-Basin of the Upper Rio das Pedras (Rio de Janeiro / RJ): Subsidies for Regeneration of Neotropical Rivers}

\author{
Maria Isabel Martinez Garcia \\ Universidade Federal do Rio de Janeiro \\ martinez.maisa@gmail.com \\ Sonia Daniela Mena Jara \\ Universidade Federal do Rio de Janeiro \\ soniamena@gmail.com \\ Mônica Bahia Schlee \\ Prefeitura da Cidade do Rio de Janeiro/Universidade Federal do Rio de Janeiro \\ monbasch@gmail.com \\ Osmar Paulino da Silva Júnior \\ Universidade Federal do Rio de Janeiro \\ osmargeo@yahoo.com \\ Ana Luiza Coelho Netto \\ Universidade Federal do Rio de Janeiro \\ ananetto@acd.ufrj.br
}

Recebido (Received): 30/05/2016 DOI: $10.11606 /$ rdg.v2i0.115801

Resumo: Este artigo descreve a metodologia adotada e resultados obtidos a partir da análise conjugada do uso do solo e da suscetibilidade a deslizamentos, indicando suas implicações na vulnerabilidade socioambiental no Alto da bacia do rio das Pedras, Jacarepaguá, Rio de Janeiro, Brasil. A metodologia utilizada envolve o mapeamento e análise do uso do solo e cobertura vegetal, das características da ocupação, dos pontos de vulnerabilidade identificados em conjunto com a comunidade e a correspondência com o mapeamento de suscetibilidade realizado para o Maciço da Tijuca por Martinez (2014). Os resultados indicam uma grande porcentagem de áreas em categoria de suscetibilidade Média-Alta $(17,33 \%)$ e Alta $(33,32 \%)$, sugerindo o grau significativo de ameaça ao qual a população residente na bacia está exposta. Adicionalmente, fatores atuais e pretéritos, tais como: deterioração da cobertura vegetal, descarga de esgoto e lixo; ocupação de zonas de inundação, estrangulamento de leitos e margens, edificações construídas imediatamente a jusante das cicatrizes de deslizamentos e o direcionamento das redes domiciliares de águas pluviais e esgotos junto às fundações das edificações, contribuem conjuntamente para aumentar a instabilidade das encostas. Análises conjugadas, associando as variáveis de caráter biofísico aos fatores antrópicos relacionados com a ocupação humana, podem contribuir para subsidiar o planejamento territorial em áreas montanhosas.

Palavras-Chave: Deslizamentos, Sedimentos, Uso do Solo e Cobertura Vegetal
Abstract: This article describes the combined analysis methodology of land use and land slide susceptibility indicating their implications on the socioenvironmental vulnerability in Alto das Pedras River Basin, Jacarepaguá District, Rio de Janeiro, Brasil. The methodology involves mapping and analysis of land use and land cover, the characteristics of the occupation, vulnerability points identified in conjunction with the community and the correspondence with the susceptibility mapping elaborated for the Tijuca Massif by Martinez (2014). The results indicate a large percentage of areas in the category Medium-High $(17.33 \%)$ and High susceptibility (33.32\%), suggesting a significant degree of threat to which the resident population in the upper basin is exposed. In addition, current and past factors such as: deterioration of vegetation, sewage and garbage discharge; occupation of flood zones, constriction of beds and banks, buildings constructed immediately downstream of landslide scars together significantly contribute to increase slope instability. Combined analysis, associating biophysical variables and anthropogenic factors related to human occupation, may contribute to support a more sustainable territorial planning in mountainous areas.

Keywords: Landslides, Sediments, Land Use and Vegetation Cover 


\section{INTRODUÇÃO}

O rápido crescimento populacional nas cidades brasileiras a partir de meados do século XX fez-se acompanhar por um processo exponencial de ocupação desordenada. Na cidade do Rio de Janeiro, a expansão urbana desordenada provocou inúmeros problemas socioambientais, principalmente na interface entre a área urbana e a floresta, gerando alterações na dinâmica hidrológica natural da região, com episódios recorrentes de deslizamentos de terra, sobretudo em períodos chuvosos.

Em fevereiro de 1996, chuvas intensas detonaram centenas de deslizamentos na porção oeste do Maciço da Tijuca, especialmente na vertente voltada para Jacarepaguá, assim como inúmeros pequenos deslizamentos ao longo das estradas que cortam o maciço (COELHO NETTO, 1996).Os deslizamentos nas encostas de Jacarepaguá causaram perdas de vidas e danos socioambientais, com alteração da configuração dos cursos d'água e a destruição total ou parcial de edificações formais e informais ao longo da trajetória dos movimentos de terra (COELHO NETTO, et al., 2012). Foi o que ocorreu no alto Rio das Pedras, área escolhida como objeto de estudo para aplicação e desenvolvimento de metodologias integradas de tratamento de esgotos e controle de sedimentos.

O lançamento indiscriminado de esgoto domiciliar nos rios e córregos da cidade está entre as principais causas de poluição das suas baías e lagoas, com ocorrência de processos de eutrofização, presença de altos níveis de coliformes fecais, sedimentação ou presença de metais pesados. A situação de degradação destes corpos d'água traz impactos sociais e econômicos, com altos custos para a saúde pública, prejuízos à conservação e proteção do meio ambiente, da paisagem e ao desenvolvimento do turismo na cidade.

$\mathrm{O}$ acesso aos serviços urbanos de infraestrutura na maioria das favelas do Rio de Janeiro está ainda mais longe dos padrões exigidos para os bairros regulares nas áreas circunvizinhas. Enquanto a maioria dos bairros tem acesso à água encanada, coleta de lixo e ao sistema de esgotamento sanitário e de drenagem, mesmo que ainda inadequados e insuficientes; nas favelas as condições são ainda mais precárias. $\mathrm{O}$ esgoto muitas vezes flui em valas a céu aberto através das vias e vielas, que também servem como canais de drenagem para as águas pluviais, aumentando o risco de doenças de vinculação hídrica. Desta forma, a combinação de fatores geológicos, geomorfológicos e bióticos somados à infraestrutura inadequada, escoamento de águas pluviais, despejo de esgoto e acúmulo de lixo nas encostas e rios que as drenam contribui para potencializar os deslizamentos de terra durante a estação chuvosa, ampliando a exposição aos riscos ambientais pela parcela da população que habita as encostas da cidade, em especial, as favelas.

A área de estudo localiza-se na sub-bacia do rio das Pedras, no bairro de Jacarepaguá, entre os paralelos $22^{\circ} 56^{\prime}$ e $22^{\circ} 59^{\prime}$ latitude sul e os meridianos de $43^{\circ} 20^{\prime}$ e $43^{\circ} 19^{\prime}$ de longitude oeste no Maciço da Tijuca entre as sub-bacias do Rio Anil ao oeste e do Itanhangá a leste, desaguando na Lagoa da Tijuca (Figura 1). Esta sub-bacia abrange $2,87 \mathrm{~km}^{2}$ e é contemplada pelos afluentes: Rio das Pedras e Rio Retiro. O foco de estudo e intervenção localiza-se na porção mais alta da sub-bacia, entre as curvas de nível 40 e 60 metros acima do nível do mar, e abrange a favela da Estrada do Sertão, residências de alto padrão e sítios de segunda residência.

Este artigo apresenta resultados obtidos a partir da análise do mapa de suscetibilidade a deslizamentos rasos e da identificação de áreas particularmente vulneráveis em campo, de forma a auxiliar no planejamento da ocupação na sub-bacia.

\section{MATERIAIS E MÉTODOS}

O mapeamento do Uso do Solo e Cobertura Vegetal é um insumo fundamental na construção de mapas de suscetibilidade a deslizamentos. Nesta pesquisa o mapeamento foi elaborado sobre a Ortofoto de 2013 (RIO DE JANEIRO/PCRJ/IPP. Mosaico de Ortofotos, 2013), considerando-se as seguintes classes: Floresta em estágio médio-avançado, Floresta em estágio inicial, gramíneas, cultivos, áreas arborizadas, áreas arbóreo-arbustivo, solo exposto, afloramentos rochosos, áreas de lazer (campo de futebol), corpos hídricos, ocupação formal e ocupação informal (Favelas). Com base nos levantamentos realizados foi atualizado o traçado da rede de canais e delimitadas as bacias de contribuição relacionadas diretamente com a área de estudo. De forma a identificar o grau de conservação das nascentes em função do uso do solo e cobertura vegetal, foram delimitadas as áreas dos mananciais localizados na parte alta das sub-bacias, tomando como referência os 50 metros estabelecidos na Lei 12.651, de 25 de maio de 2012 (Brasil, 2012). 


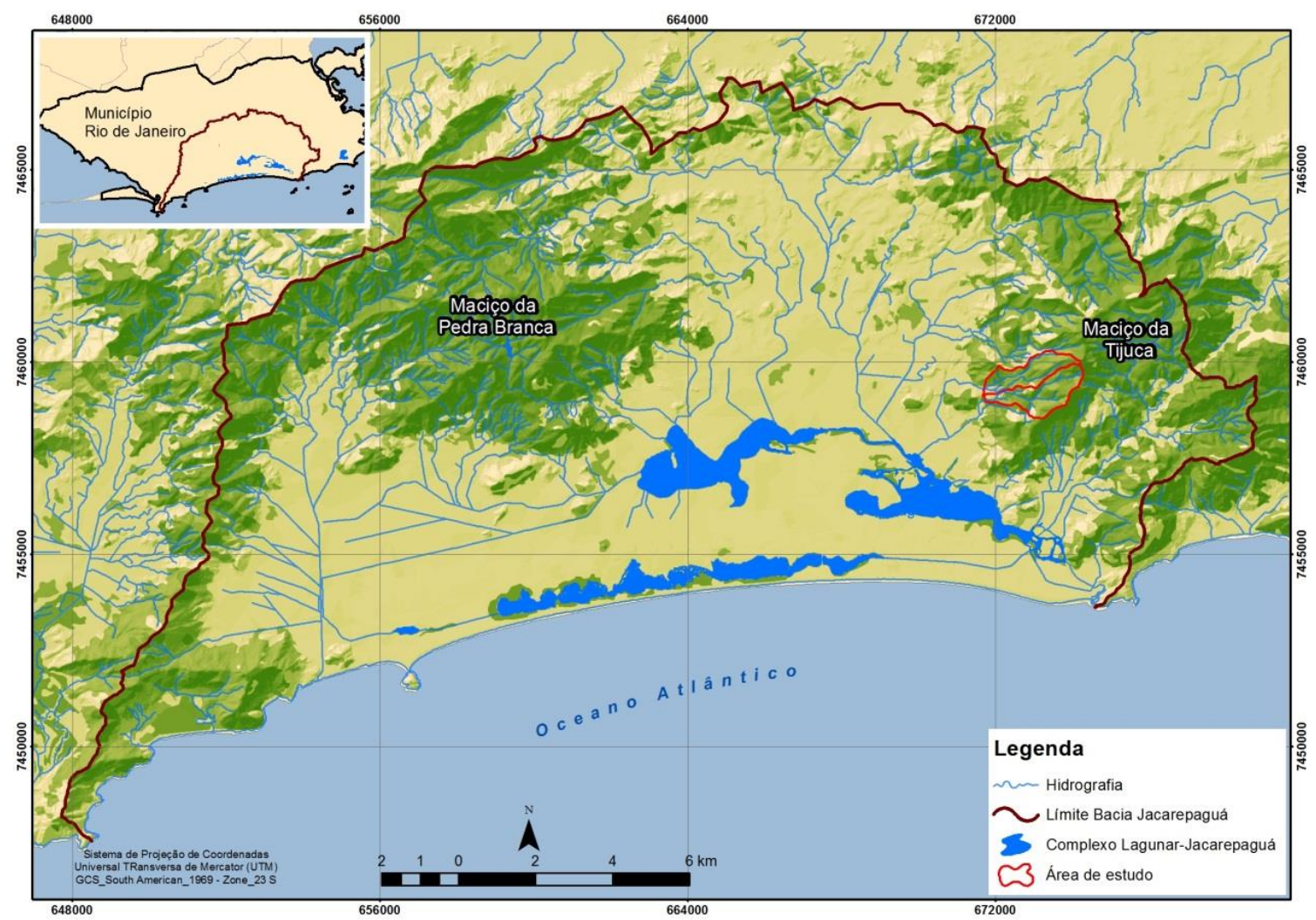

Figura 1: Sistema Hidrográfico da Baixada de Jacarepaguá, Rio de Janeiro (RJ), onde se insere a sub-bacia do rio das Pedras. Fonte: autores.

O método aplicado para a caracterização da ocupação urbana e da problemática ambiental abrange as seguintes etapas: a) preparação e tratamento da base de dados; b) elaboração dos mapas de uso e cobertura do solo, c) características da ocupação urbana d) registro de áreas vulneráveis (cicatrizes de deslizamento de 1996, pontos de extravasamento do rio e de descarga de esgoto).

O levantamento e mapeamento da ocupação urbana (formal e informal) no alto das duas sub-bacias (Pedras e Retiro) abrangeu a identificação dos traçados das vias internas nas áreas favelizadas, tipos de uso urbano (residencial, misto, institucional, comercial, industrial, galpão, laje e terreno vazio) e número de pavimentos das edificações, a partir de metodologia desenvolvida por Schlee (2011).

Este mapeamento da ocupação foi fundamental para atualizar a estimativa do contingente populacional de moradores da favela (o levantamento do número de domicílios demonstrou que os dados do Censo do IBGE de 2010 estavam defasados) e permitiu fazer um cálculo aproximado da população que habita o Alto Rio das Pedras e, por conseguinte, do volume de esgoto produzido no alto das sub-bacias com base na literatura (SPERLING, 1996; VIANNA, 2015) e nos levantamentos de campo.

Para a construção do mapa de suscetibilidade, foi utilizado o Método Analítico - Integrativo, (COELHO NETTO et al., 1999), que envolve sucessivas etapas de análises, indutivas e dedutivas, intercaladas pelo cruzamento de mapas temáticos submetidos a diferentes etapas de agregações e desagregações das informações cartografadas. As etapas são: a) preparação e tratamento da base de dados; b) síntese temática considerando a reclassificação e redefinição das classes e elaboração dos mapas de cada fator (1.Hidro-geomorfológico: índice de eficiência de drenagem, declividade e índice de posicionamento topográfico; 2.Cobertura vegetal e uso do solo e 3.Geologia), por comportamento semelhante; c) definição de pesos determinados por especialistas e segundo a importância relativa de cada fator; d) cálculo e elaboração do mapa síntese.

Em seguida, o mapa de suscetibilidade foi cotejado com a caracterização da ocupação urbana; vias, usos e número de pavimentos das edificações. Com o objetivo de identificar riscos adicionais na área de estudo, foram também registrados os pontos de descarga de esgoto nos rios, que além do risco sanitário à população, contribuem para agravar a vulnerabilidade a deslizamentos e os processos erosivos às margens dos cursos d'água devido ao escoamento contínuo de água nas encostas. De modo a comparar com as áreas atingidas por deslizamentos em eventos anteriores, foi utilizado o mapeamento das cicatrizes de 
deslizamentos de 1996 (Cruz, 2000; Negreiros, 2011), mensurando o grau de superposição destas com as categorias de Suscetibilidade Médio-Alto e Alto. Adicionalmente, foram levantadas informações históricas no local como o nível de extravasamento do leito do rio em 1996 e a mudança de configuração em alguns trechos após esse evento. Como recorte espacial de análise, utilizou-se as sub-bacias de contribuição que atravessam a comunidade.

Usando como referência os autores Girão et al. (2007), fatores antrópicos que potencializam a instabilidade das encostas e o risco potencial a deslizamentos e inundações em áreas previamente categorizadas como suscetíveis foram analisados. Esta informação pode ajudar na compreensão do comportamento das bacias durante os eventos extremos de chuva e, portanto, contribuir para a prevenção, conscientização e empoderamento da comunidade frente a situações de risco. A Figura 2 sintetiza a metodologia adotada.

\begin{tabular}{|c|c|c|}
\hline $\begin{array}{l}\text { Produtos elaborados / } \\
\text { cartografados }\end{array}$ & Parâmetros analisados & Tipo ou objetivo da análise \\
\hline OCUPAÇÃO URBANA & $\begin{array}{l}\text { - Número de edificações } \\
\text { - Distribuição das edificações } \\
\text { - Traçado das vias internas da comunidade favelizada } \\
\text { - Tipo de ocupação: uso e número de pavimentos }\end{array}$ & $\begin{array}{l}\text { Levantamento do número de domicílios e } \\
\text { estimativa da população com base na } \\
\text { relação utilizada pelo IBGE; Conhecimento } \\
\text { do montante populacional sob risco }\end{array}$ \\
\hline $\begin{array}{l}\text { MAPA DE USO E COBERTURA } \\
\text { DO SOLO }\end{array}$ & $\begin{array}{l}\text { - \% de cobertura por classe } \\
\text { - Mapeamento de mananciais (APPs) }\end{array}$ & $\begin{array}{c}\text { Composição da bacia e insumo para mapa } \\
\text { suscetibilidade }\end{array}$ \\
\hline $\begin{array}{l}\text { MAPA DE SUSCETIBILIDADE A } \\
\text { DESLIZAMENIOS }\end{array}$ & $\begin{array}{l}\text { Classificação das áreas em: } \\
\text { - Baixa suscetibilidade } \\
\text { - Media-Alta suscetibilidade } \\
\text { - Alta suscetibilidade }\end{array}$ & $\begin{array}{l}\text { Determinação do grau de risco da } \\
\text { comunidade com base em fatores } \\
\text { Geológicos, Hidro-geomorfológicos e de } \\
\text { Uso e Cobertura do Solo }\end{array}$ \\
\hline $\begin{array}{l}\text { LEVANTAMENTO DE REGISTROS } \\
\text { HISTÓRICOS }\end{array}$ & $\begin{array}{l}\text { - Cicatrizes dos deslizamento s de } 1996 \text { (Cruz, } 2000 \text { e } \\
\text { Negreiros, 2011) } \\
\text { - Aumento nível do rio evento } 1996 \\
\text { - Mudança morfológica curso de água }\end{array}$ & $\begin{array}{l}\text { Análise da relação de eventos passados com } \\
\text { nível de risco atual (Superposição com as } \\
\text { áreas de Media-Alta e Alta suscetibilidade) }\end{array}$ \\
\hline $\begin{array}{l}\text { FAIORES ANIRÓPICOS QUE } \\
\text { POTENCIALIZAM } \\
\text { INSTABILIDADE DAS ENCOSTAS } \\
\text { EDEIERIORAÇÃO AMBIENIAL }\end{array}$ & $\begin{array}{l}\text { - Pontos de descarga esgoto ao longo dos rios } \\
\text { - Vazamentos em captações irregulares de água } \\
\text { - Fluxo concentrado de águas chuvas } \\
\text { - Cortes terreno ou movimentos do solo } \\
\text { - Presença de lixo ou entulho em encosta } \\
\text { - Ocupação urbana das margens dos rios } \\
\text { - Assoreamento de canais }\end{array}$ & $\begin{array}{l}\text { Análise de fatores antrópicos que aumentam } \\
\text { risco potencial em áreas previamente } \\
\text { categorizadas como suscetíveis, } \\
\text { contribuindo para eventos de deslizamento } \\
\text { e inundações }\end{array}$ \\
\hline
\end{tabular}

Figura 2: Esquema metodológico adotado. Fonte: autores.

\section{RESULTADOS E DISCUSSÕES}

Com base nos levantamentos de campo e mapeamentos realizados, obtivemos o número de domicílios (favela e não-favela), calculamos o número de habitantes (em 2016) do alto rio das Pedras e da favela da Estrada do Sertão e estimamos a produção local de esgoto de forma mais acurada. Tomou-se por base a média de pessoas/domicílio adotada pelo Censo IBGE 2010: 2,86 (não-favelas, ou não aglomerados subnormais - AGSN/IBGE); 3,26 (favelas, AGSN/ domicílios particulares ocupados).

Desta forma, calculamos que o contingente populacional no alto rio das Pedras (em 2016) equivale a: 1.451 habitantes na favela da Estrada do Sertão +237 habitantes área formal $=1.688$ habitantes no Alto Pedras/Retiro. Quanto à estimativa de produção de esgoto, 3,5 1/s é o valor do aporte no alto Rio das Pedras, incluindo as áreas de ocupação formal e informal. Evidenciou-se assim um aumento da população da favela da Estrada do Sertão de 324 habitantes entre 2010 e 2016. Segundo os dados do Censo de 2010, a favela da Estrada do Sertão contava com 1127 habitantes.

O mapeamento da ocupação e do tipo de uso urbano demonstrou que o uso predominante, tanto no Alto rio das Pedras/Retiro como na favela da Estrada do Sertão, é o residencial. Em seguida, destacam-se o uso misto e o institucional. O uso comercial e o institucional localizam-se ao longo dos eixos de circulação de veículos. Na favela predominam as edificações de dois pavimentos, mas foram encontradas edificações de até 5 pavimentos. A Figura 3 apresenta os resultados do mapeamento de Uso do solo e cobertura vegetal realizado na sub-bacia do rio das Pedras/Retiro: 


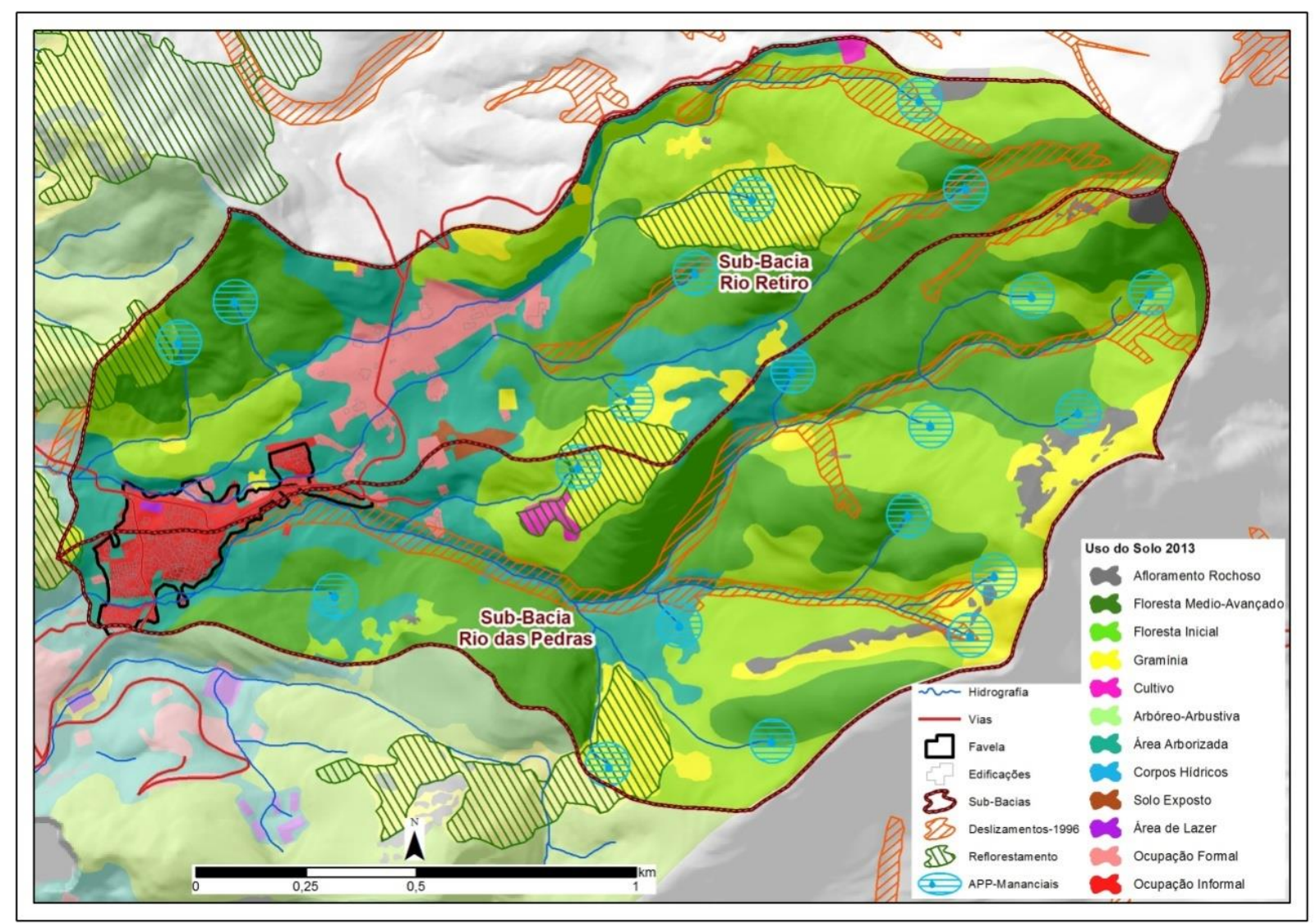

Figura 3: Mapa de uso do solo e cobertura vegetal com as cicatrizes do deslizamento de 1996. Fonte: autores

O trecho analisado (alto das sub-bacias dos rios Pedras e Retiro), ainda conta com cerca de $92 \%$ de cobertura vegetal, em contraste com cerca de $8 \%$ de áreas urbanizadas (o restante inclui afloramentos rochosos, corpos hídricos e solo exposto) (Tabela 1). A ocupação concentra-se ao longo dos fundos de vale, entre as curvas de nível de $40 \mathrm{~m}$ e $60 \mathrm{~m}$ acima do nível do mar, onde torna-se densa. As áreas com ocupação mais densa coincidem com as áreas ocupadas por favelas.

Na figura anterior é possível ver as cicatrizes de deslizamento do ano 1996 acompanhando os canais de drenagem na área de análise. Estas evidenciam o nível de ameaça que a ocupação urbana provoca quando se instala às margens dos rios nestas sub-bacias. No caso do Rio das Pedras, em particular, tendo em vista a história do lugar e o registro geomorfológico evidenciado pelas cicatrizes de deslizamentos que ocorreram no passado, o risco à população é evidente. Além disso, como indicado por COELHO NETTO (2005), as erosões subsequentes em solos expostos nas clareiras-cicatrizes de deslizamentos continuam alimentando altas cargas de sedimentos nos canais principais do maciço montanhoso, contribuindo para a manutenção do processo de assoreamento nos canais drenantes das baixadas circundantes. Este constitui mais um agravante ao risco de inundação em eventos de precipitação extraordinária. Pesquisas relativas ao assoreamento da Lagoa da Tijuca, onde desembocam os rios que percorrem a área de estudo, confirmam a magnitude do problema de transporte e acúmulo de detritos nas lagoas de Jacarepaguá e da Barra da Tijuca, como resultado dos deslizamentos registrados no Maciço da Tijuca, nos anos 1966-1967 e 1996 (MENA, 2014).

Em relação à cobertura vegetal, observa-se na Tabela 1 a presença de Gramíneas (10,3\%) e Floresta inicial $(28,8 \%)$ respectivamente, várias das quais localizadas em áreas de nascentes. É importante mencionar que as áreas de nascente são objeto de proteção oficial no Código Florestal (2012), sob a figura de Áreas de Proteção Permanente. Estas áreas, que podem ser observadas na Figura 3, encontram-se desprovidas de vegetação ou com vegetação degradada e estão situadas em áreas de alta declividade, contribuindo para alimentar o fluxo sedimentar e impactando a qualidade da água por meio do carregamento do material sólido e poluentes para o rio durante eventos de grande precipitação. Por outro lado, a retirada da vegetação nas áreas de nascente em rios que abastecem diretamente a comunidade da Estrada do Sertão, compromete os processos de infiltração da água no solo, diminuindo, por sua vez, a disponibilidade hídrica na bacia. 
Tabela 1: Percentual da cobertura vegetal e ocupação do solo para cada uma das categorias.

\begin{tabular}{|c|c|c|c|}
\hline \multirow{2}{*}{\multicolumn{2}{|c|}{ Classes }} & \multicolumn{2}{|c|}{ Sub-bacias } \\
\hline & & \multirow{2}{*}{$\begin{aligned} \mathbf{k m}^{2} \\
1,0317\end{aligned}$} & \multirow{2}{*}{$\begin{array}{l}\% \\
35,99\end{array}$} \\
\hline Floresta Média Avançada & $\begin{array}{c}\text { Floresta Média } \\
\text { Avançada }\end{array}$ & & \\
\hline Floresta Inicial & \multirow{2}{*}{ Floresta Inicial } & 0,8269 & 28,84 \\
\hline Área Arborizada & & 0,4828 & 16,84 \\
\hline Gramínea & \multirow{3}{*}{ Gramíneas } & 0,2975 & 10,38 \\
\hline Cultivo & & 0,0114 & 0,40 \\
\hline Solo Exposto & & 0,0079 & 0,28 \\
\hline Área de Lazer & \multirow{3}{*}{ Ocupação } & 0,0014 & 0,05 \\
\hline Ocupação Formal & & 0,0876 & 3,06 \\
\hline Ocupação Informal & & 0,0718 & 2,50 \\
\hline Afloramento Rochoso & Afloramento Rochoso & 0,0479 & 1,67 \\
\hline & Total & 2,8669 & 100,0 \\
\hline
\end{tabular}

A Figura 4 apresenta o resultado da análise de suscetibilidade a deslizamentos realizado na área de estudo, com base no trabalho de Martínez (2014). Esta figura mostra a grande porcentagem de áreas em categoria de suscetibilidade Média- Alta $(17,33 \%)$ e Alta $(33,32 \%)$ acima da cota $40 \mathrm{~m}$ sugerindo o grau significativo de ameaça ao qual a população residente na bacia está exposta, como observado na Tabela 2. $\mathrm{Na}$ área delimitada como favela, 77,95\% da ocupação localiza-se em áreas com Media Suscetibilidade, e 18,61\% em área de Alta Suscetibilidade. A maioria das áreas classificadas como Alta Suscetibilidade está localizada às margens dos rios ou próxima aos divisores de drenagem. Uma das maiores manchas de médiaalta suscetibilidade está localizada a montante da favela da Estrada do Sertão, envolvendo-a.

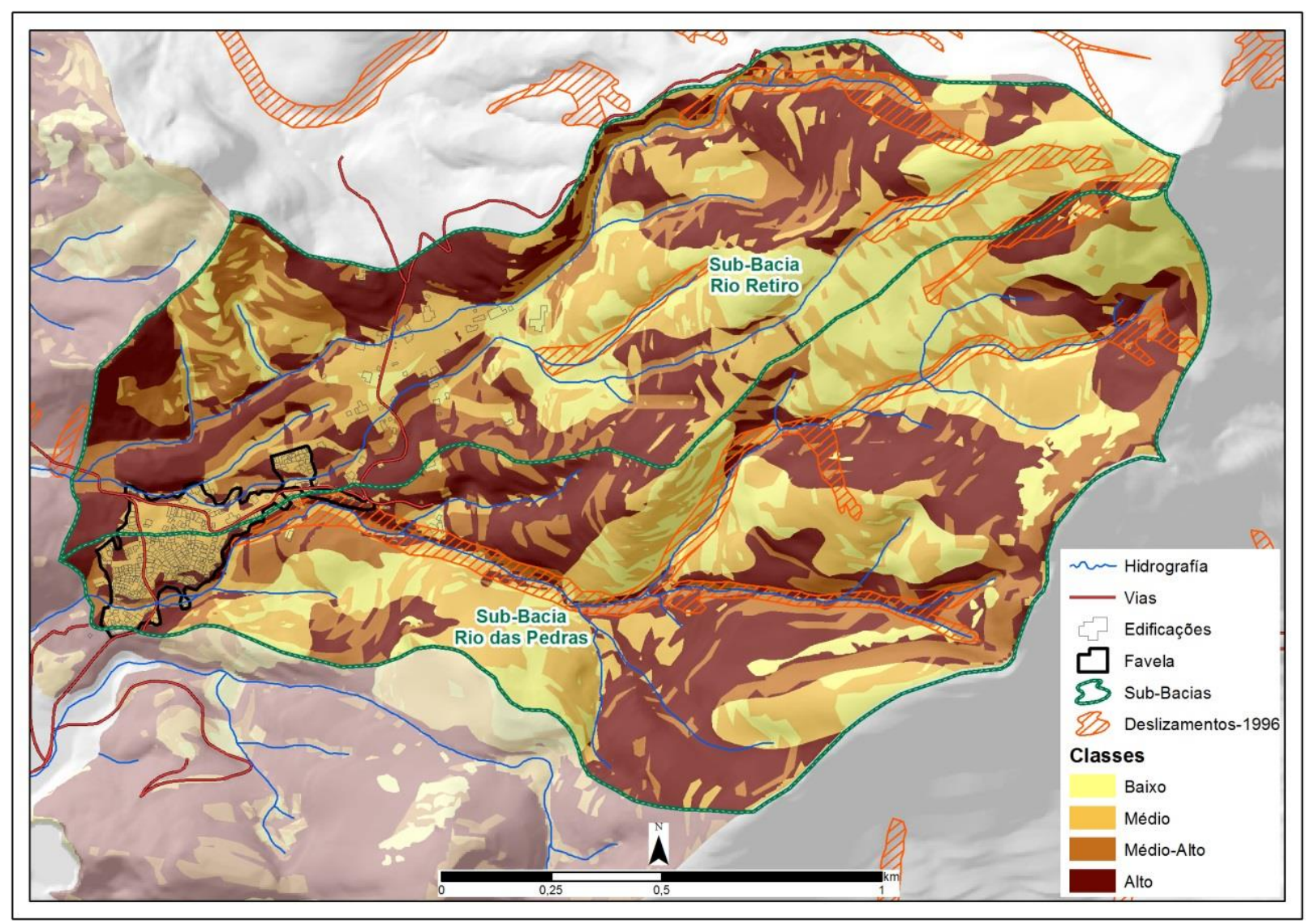

Figura 4: Mapa de suscetibilidade a deslizamentos. Fonte: Martinez, 2014, atualizado em 2016. 
Tabela 2: Percentual de áreas com suscetibilidade a deslizamentos

\begin{tabular}{|l|c|c|c|}
\hline & \multicolumn{3}{|c|}{ Porcentual de Áreas (\%) } \\
\hline Classes & $\begin{array}{c}\text { Sub-bacias } \\
\left(\mathbf{2 , 8 6 6 8 5 5} \mathbf{~ k m}^{\mathbf{2}}\right)\end{array}$ & $\begin{array}{c}\text { No recorte da favela } \\
\left(\mathbf{0 , 0 8 3 5 9 1} \mathbf{~ k m}^{\mathbf{2}}\right)\end{array}$ & $\begin{array}{c}\text { No recorte das cicatrizes } \\
\left(\mathbf{0 , 2 7 4 0 3 5} \mathbf{~ k m}^{\mathbf{2}}\right)\end{array}$ \\
\hline Alta & 33,32 & 18,61 & 28,78 \\
\hline Media-alta & 17,33 & 3,43 & 20.91 \\
\hline Media & 29,24 & 77,95 & 25.57 \\
\hline Baixa & 20.1 & 0,02 & 24,74 \\
\hline
\end{tabular}

Do mesmo modo, observa-se ampla superposição entre as áreas coberta pelas cicatrizes do deslizamento ocorrido em 1996 (COELHO NETTO, 1997) e as áreas classificadas como em risco, onde 49,69\% da área das antigas cicatrizes continuam sendo áreas de Media-Alta ou Alta suscetibilidade a deslizamentos. Isto confirma a vulnerabilidade das edificações construídas às margens dos dois rios, tanto nos assentamentos de tipo informal quanto em alguns lotes formais (Figura 4). É relevante indicar que os movimentos de massa podem afetar não apenas as áreas circunscritas aos canais de drenagem - no local delimitado pelas cicatrizes - mas também uma área mais abrangente, tendo em vista o deslocamento do material removido e sua posterior deposição encosta abaixo.

A Figura 5 enfatiza a importância e utilidade dos dados coletados em campo, em conjunto com a comunidade local, uma fonte valiosa de informação atuando como suporte adicional à análise técnica de suscetibilidade na área. As elipses e círculos vermelhos expressam a somatória de fatores atuais e históricos que contribuem para aumentar o risco, tais como: alteração da morfologia dos rios após os eventos de deslizamentos; descarga de esgoto e lixo; ocupação de zonas de inundação; estrangulamento do rio devido à ocorrência de edificações no leito e margens; cruzamento de vias sobre leitos de rios; edificações localizadas imediatamente a jusante das cicatrizes dos deslizamentos pretéritos; direcionamento das redes domiciliares de águas pluviais e esgotos junto às fundações das edificações, causando instabilidade; deterioração da cobertura vegetal e ocupação às margens dos rios em áreas de alta declividade, os quais, em conjunto, contribuem significativamente para aumentar o risco a deslizamentos.

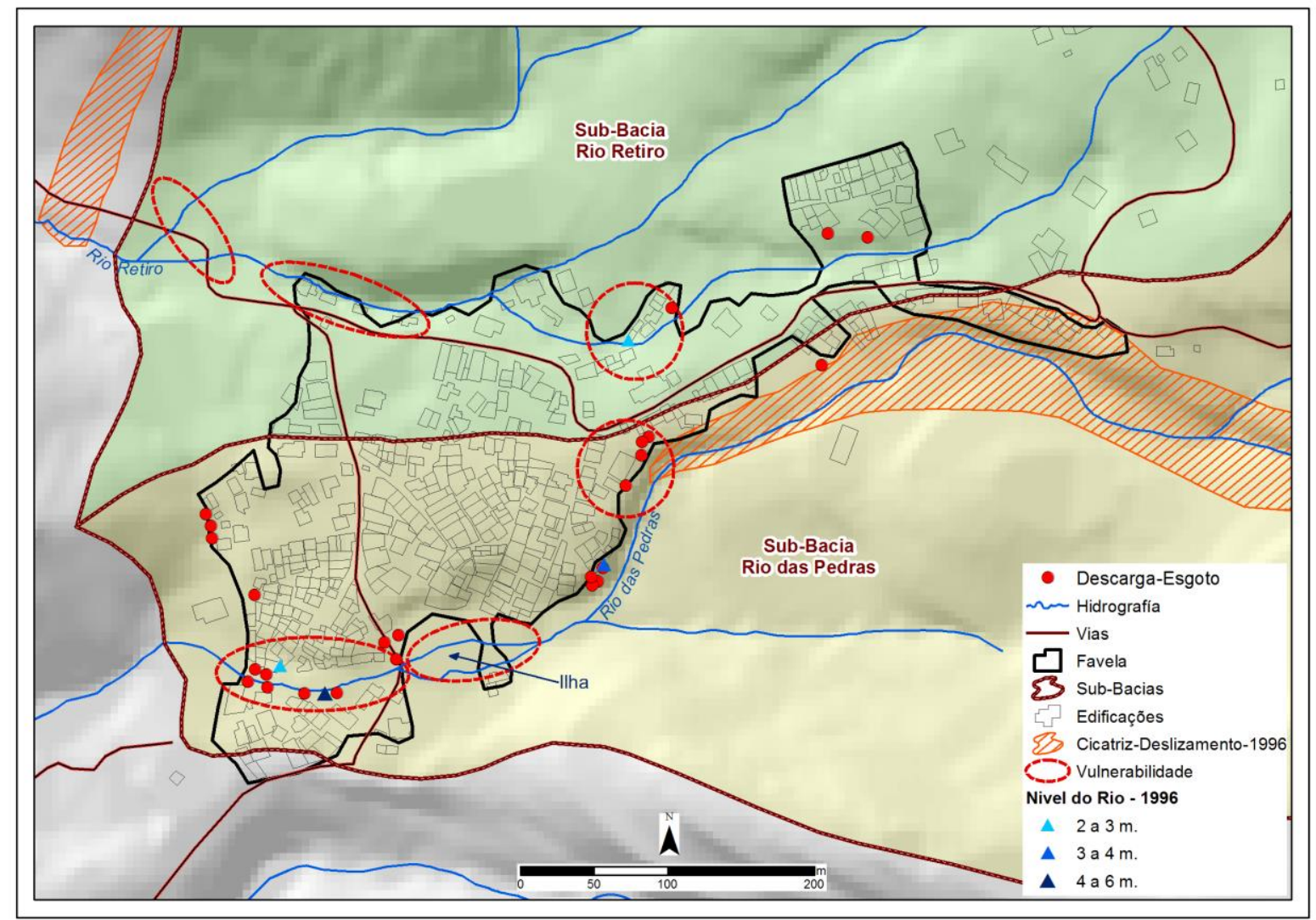

Figura 5: Identificação das áreas vulneráveis locais. Fonte: autores. 
Como mostra a Figura 5, e segundo a população local, o rio alcançou uma altura de até 6 metros em alguns pontos durante o evento extremo de precipitação de 1996. O regime hídrico do rio aumentou de forma drástica durante o evento, gerando uma alteração na geomorfologia dos canais. Assim, em um determinado trecho do seu curso principal, o rio bifurcou-se em função da erosão e do arrasto do material sedimentar, dando origem a uma pequena ilha, com 1.321,43 $\mathrm{m}^{2}$. Esta ilha se formou logo abaixo de um meandro pronunciado a montante do qual o canal foi escavado severamente em 1996. Neste local (que coincide com o final da cicatriz do deslizamento de 1996) ainda há desbarrancamentos isolados às margens do rio (Pedras). Esta situação de risco é agravada pela existência de condutores de águas pluviais e esgotos que direcionam seus efluentes ao rio junto à base das edificações. Há também evidência de deslocamento de blocos de rocha das áreas de encosta para o leito do rio, demonstrando a potência do movimento de massa.

Em relação ao mapeamento da localização dos pontos de despejo de esgoto, estes se aglutinam em quatro áreas ao longo do rio das Pedras e duas ao longo do rio Retiro (Figura 5). O despejo de esgoto, além de prejudicar a qualidade de água e aumentar o risco sanitário, contribui para que o escoamento superficial de águas poluídas às margens dos cursos d'água se torne contínuo. Esta situação tende a potencializar os processos erosivos e a deflagração de movimentos de massa nas encostas já fragilizadas devido à ocorrência de deslizamentos pretéritos.

\section{CONSIDERAÇÕES FINAIS}

Conforme demonstram os resultados obtidos até o momento, a caracterização da ocupação urbana, com base nos dados coletados em campo e nas informações fornecidas pela comunidade local, foi de grande utilidade para identificar as áreas vulneráveis a riscos ambientais em nível local.

A identificação de áreas vulneráveis a riscos ambientais em domínios montanhosos (deslizamentos e inundações) em conjunto com a comunidade, por sua vez, contribui como suporte adicional à análise técnica de suscetibilidade.

A rota das antigas cicatrizes de 1996 continua sendo uma área de alto risco a deslizamento. Uma das maiores cicatrizes aponta em direção à comunidade da Estrada do Sertão ao longo do fundo de vale. E é justamente a área na envoltória da comunidade localizada às margens dos rios que apresenta maior suscetibilidade.

Assim, torna-se fundamental considerar a sinergia entre os fatores avaliados, associando as variáveis de caráter biofísico aos fatores antrópicos relacionados com a ocupação humana nas áreas de encosta, que tendem a aumentar os riscos e a complexidade da problemática.

Neste sentido, um trabalho em conjunto com a comunidade, de divulgação e troca dos conhecimentos adquiridos, bem como de conscientização sobre os riscos, fatores e medidas que a população possa adotar e interferir positivamente parece ser o melhor caminho a seguir. Para isso, é primordial engajar e atrair a atenção da população através da realização de palestras informativas, oficinas práticas sobre medidas de prevenção ao risco de desastres, discussões sobre saneamento ambiental e métodos de tratamento de esgoto e finalmente na escolha do sistema de tratamento a ser adotado, para que este se adeque às condições locais.

A fase seguinte do projeto compreende a instalação de uma estação hidro-fluvio-sedimentológica que irá proporcionar informações sobre a resposta do rio a eventos de chuva de forma contínua. Ao mesmo tempo, será monitorada a análise da qualidade da água em diversos pontos ao longo do rio, determinando o nível de poluição provocada pelo despejo de esgoto e sua distribuição espacial na área de estudo.

Estas análises conjugadas podem, por sua vez, contribuir para subsidiar o planejamento territorial em áreas montanhosas, de modo a reduzir o alcance dos desastres causados por eventos de deslizamento.

\section{AGRADECIMENTOS}

Agradecemos à Fundação de Amparo à Pesquisa do Estado do Rio de Janeiro-FAPERJ pelo fomento à presente pesquisa através do - Edital 16/2014, "Programa Apoio a Projetos de Extensão e Pesquisa - EXTPESQ - 2014". Aos moradores da Estrada do Sertão, em especial a Claudio Jeronimo da Silva, Claudia Maria Helena da Silva, Paulo José de Almeida dos Santos, Reginaldo Silva, Jerry Nilson da Silva, Irineia Rodrigues, Beraldo dos Santos, Conceição da Silva, Luiz Miguel Costa dos Santos, Lucia Santos Alcântara, Angélica Oliveira e Lindalva da Conceição Dias. 


\section{REFERÊNCIAS}

ALMEIDA, N. V.; CUNHA, S. B; NASCIMENTO, F. R. A cobertura vegetal e sua importância na análise morfodinâmica da bacia hidrográfica do rio Taperoá - Nordeste do Brasil/ Paraíba. Revista Geonorte, v. 3, n. 4, edição especial, p. 365-378, 2012. Disponível em: <https://drive.google.com/file/d/0B8gWTN_hgGp0V0w1c0tiSm9SRzg/edit?pref=2\&pli=1>.

BRASIL. Lei 12.651, de 25 de maio de 2012. Altera a Lei 4.771 de 15 de setembro de 1965, que institutiu o Código Florestal. Diário Oficial [da] República Federativa do Brasil, Brasília, DF, 28 mai. 2012. Disponível em: http://www.planalto.gov.br/ccivil_03/_ato2011-2014/2012/lei/112651.htm. Acesso em: 22 ago. 2016.

COHIDRO, Estudo de Impacto Ambiental para Estabilização da Barra do Canal de Sernambetiba e sua Interligação com as Lagoas de Jacarepaguá, Tijuca e Marapendi. Consultoria estudos projetos SERLA, 2006.

COELHO NETTO, A. L. Produção de sedimentos em bacias fluviais florestadas do maciço da Tijuca, RJ: respostas aos eventos extremos de fevereiro de 1996. In: Anais do II Encontro Nacional de Engenharia de Sedimentos, RJ, p.199-209, 1996.

COELHO NETTO, A.L. Catastrophic Landscape Evolution in a Humid Region (SE Brasil): Inheritances from Tectonic, Climatic and Land Use Induced Changes. In:Supl. Geogr. Fis.Dinam. Quat. Vol. III; Fourth International Conference on Geomorphology: Bologna, Italy; pp. 21-48, 1999.

COELHO NETTO, A. L.; MACHADO, L. O.; CASTRO, M. C.; OLIVEIRA, R. R.; LACERDA, W. A.; AVELAR, A. S.; FERNANDES, M. C.; LEÃO, O. M. R. Rio de Janeiro/Secretaria Municipal do Meio Ambiente (Processo14/000.831/99): Estudos de qualidade ambiental do geoecossistema do Maciço da Tijuca - subsídios à regulamentação da APARU do Alto da Boa Vista. 2000.

COELHO NETTO, A. L. A interface florestal-urbana e os desastres naturais relacionados à água no Maciço da Tijuca: desafios ao planejamento urbano numa perspectiva sócio-ambiental. Revista do Departamento de Geografia, 46-60, 2005.

COELHO NETTO, A.L. A Geoecologia e a Arquitetura da Paisagem do Rio de Janeiro no Século XXI: Da Degradação à Reabilitação Funcional da Cidade e da Floresta Atlântica Remanescente. In Águas Urbanas: A Regeneração Ambiental como Campo Disciplinar Integrado; TANGARI, V,75-92, 2007.

COELHO NETTO, A.L.; AVELAR, A.; FERNANDES, M.; LACERDA, W. Landslide susceptibility in a mountainous geoecosystem, Tijuca Massif, Rio de Janeiro: The role of morphometric subdivision of the terrain. Geomorphology, 7, 120-131, 2007.

COELHO NETTO, A.L.; AVELAR, A.S.; MUlUlO SATO A.; ACCIOLY DIAS.M.; BAHIA SCHLEE M.; NEGREIROS A.B. Vulnerabilidade em Geoecossistemas montanhosos e Desastres causados por deslizamentos na Interface Floresta-Urbana: Controles Geológicos Geomorfológicos e Geoecológicos. In Desastres Naturais - Suscetibilidade e Riscos - Mitigação e Prevenção - Gestão e Ações Emergenciais. COPPE/UFRJ - Rio de Janeiro, Lacerda W.A., et al.(Org.) cap.5, p.63-80, 2012.

CRUZ,E.S. Reativação erosiva e revegetação em cicatrizes erosivas de movimentos de massa: estação experimental da cicatriz do pico do Papagaio/maciço da Tijuca - RJ. Dissertação de Mestrado. Rio de Janeiro: Programa de pós-graduação em Geografia, UFRJ, 2000.

DIAS, A. P. E ROSSO, T. C. Análise dos Elementos Atípicos do Sistema de Esgoto - Separador Absoluto na Cidade do Rio de Janeiro, Engevista. V.13. n.3, p. 177-192, 2011.

IBGE, Censo Demográfico 2010.2 Disponível em: <http://www.ibge.gov.br/home/estatistica/populacao/censo2010/caracteristicas_da_populacao/default_car acteristicas_da_populacao.shtm.> Último acesso em 25/09/2015.

INSTITUTO TRATA BRASIL/SNIS - Ministério das Cidades 2011. Benefícios Econômicos da Expansão do Saneamento Básico à Sociedade dos Municípios do Entorno da Baía da Guanabara. 2001. Disponível em <http://cebds.org.br/wp-content/uploads/2014/06/ITB-Ba\%C3\%ADa.pdf.> Último acesso em $07 / 10 / 2014$.

GIRÃO O. ; CORRÊA A.C. de B., GUERRA, A. J. T. Encostas Urbanas como Unidades de Gestão e Planejamento, a partir do Estudo de Áreas a sudoeste da cidade do Recife - PE. Revista de Geografia. v. 24, n. 3, 2007 
MARQUES, J. S. A participação dos rios no processo de sedimentação da baixada de Jacarepaguá. 2v. São Paulo, UNESP (Rio Claro), Instituto de Geociências e Ciências Exatas, Tese de Doutorado em Geografia, 245p, 1990.

MARTínEZ G.,M.I. Avaliação da Suscetibilidade de Terreno para Deslizamentos Rasos: Maciço da Tijuca - Rio de Janeiro. Dissertação de Mestrado. Rio de Janeiro: Programa de pós-graduação em Geografia, UFRJ, 2014.

MENA JARA, S. D. Análise das mudanças espaço-temporais na lagoa da Tijuca e o papel da Faixa Marginal de Proteção. Dissertação de Mestrado. Rio de Janeiro: Programa de pós-graduação em Geografia, UFRJ, 2014.

NEGREIROS, A.B. Recuperação de Floresta Atlântica e Resultante Hidro-Erosiva em Clareiras de Deslizamentos nas Encostas Íngremes do Maciço da Tijuca, RJ. Dissertação de Mestrado. Rio de Janeiro: Programa de pós-graduação em Geografia, UFRJ, 2011.

RIO DE JANEIRO/Prefeitura da Cidade do Rio de Janeiro/ Instituto Municipal de Urbanismo Pereira Passos. Mosaico de Ortofotos 2013 (Mosaico_2013_UTM). Rio de Janeiro: Armazém de Dados/IPP/PCRJ. Disponível em: http://portalgeo.rio.rj.gov.br/. Acesso em: 22 ago. 2016.

SHAHABI, H., \& HASHIM, M. Landslide susceptibility mapping using GIS-based statistical models and Remote sensing data in tropical environment. Scientific Reports, 5:9899, 2015.

SCHLEE, M.B. Landscape Change Along the Carioca River, Rio de Janeiro, Brazil; Master Thesis, The Pennsylvania State University, University Park, USA, 2002.

SCHLEE, M.B., ANDRADE, R., DIAS, M.A., Eds.; PROARQ-FAU/UFRJ, ETU/UFRJ, ABAP-RIO, IPP/PCRJ: Rio de Janeiro, Brazil, 2007.

SCHLEE, M.B. A ocupação das encostas do Rio de Janeiro: morfologia, legislação eprocessos socioambientais. Tese de Doutorado em Arquitetura. Rio de Janeiro:Universidade Federal doRio de Janeiro, Rio de Janeiro, 2011.

SCHLEE, M.B.; TAMMINGA, K. R. e TÂNGARI, V. R. A method for gauging landscape change as a prelude to urban watershed regeneration: the case of the Carioca river, Rio de Janeiro. In: Sustainability, 4, 2054-2098, 2012.

SCHNEIDER, L.; CASTRO, A. Considerações Sobre os Impactos Socioambientais na Sub-Bacia do rio Das Pedras RJ. Niterói: Universidade Federal Fluminense. Instituto de Geociências/Departamento de Geografia, 2012.

SPERLING, Marcos Von. Introdução à qualidade das águas e ao tratamento de esgotos. Belo Horizonte: Editora UFMG, 243p,1996. Disponível em <https://drive.google.com/folderview?id=0B16odcwGFHvfkhIVkxuVTBhcXNGQmJ3T0VGbUloZmJzaEt0dTRqNXViV2NrbkEyRjlFLUk\&usp=sharin g>

VIANNA, P. Relatório do Macrodiagnóstico de Infraestrutura de Saneamento da Cidade do Rio de Janeiro. Rio de Janeiro: Prefeitura da Cidade do Rio de Janeiro/Secretaria Municipal de Urbanismo/Coordenadoria de Macro Planejamento, 2015. 